\title{
MARKERS OF ENDOTHELIAL DYSFUNCTION AND THEIR PROGNOSTIC VALUE IN CHILDREN WITH ACUTE LYMPHOBLASTIC LEUKEMIA
}

\author{
Odinets $Y^{1}$., Kondratiuk T. ${ }^{1}$ Koida $M .^{2}$ \\ ${ }^{1}$ Kharkiv National Medical University, Ukraine \\ ${ }^{2}$ Kharkiv City Clinical Children's Hospital № 16, Ukraine \\ https://doi.org/10.35339/ic.7.1.10-16
}

\begin{abstract}
Acute lymphoblastic leukemia (ALL) in children is associated with development of a large number of serious complications. Inflammatory and pro-aggregation activation of endothelial cells accompanies the course of leukemia. Endothelial dysfunction (ED) is believed to be an integral part of the pathogenic link of ALL and its complications. Materials and methods. The content of nitric oxide in serum with the concentration of its stable metabolites $-\mathrm{NO}_{2}$, $\mathrm{NO}_{3}$ - was determined in 73 patients with ALL and 19 healthy children. Determination of nitric oxide was performed at different stages of the presentation of ALL: 49 children were examined during the manifestation of leukemia (group 1A), of whom 36 children (group 1B) were re-examined during the first course of treatment - induction of remission. Also 8 children (group 2) were examined during supportive therapy and 16 children (group 3) who underwent complete chemotherapy treatment. Results. The study showed that nitrite increase and nitrate reduction secondary to reduced total nitric oxide content during all treatment periods in children with ALL. In addition, signs of endothelial dysfunction were recorded in patients after treatment. ROC analysis showed that reduction in $\mathrm{NO}_{2}$ content lower than $12.31 \mu \mathrm{mol} / 1$ and the sum of $\mathrm{NO}_{2}+\mathrm{NO}_{3}$ lower than $32.99 \mu \mathrm{mol} / 1$ significantly had a negative effect on the survival of children with ALL. Conclusions. ED accompanies the course of ALL in children. Determination of nitric oxide is of diagnostic and prognostic importance in patients with leukemia. The critical fall in the concentration of $\mathrm{NO}$ and $\mathrm{NO}_{2}$ accompanies development of multiple organ failure with fatal outcome in children with ALL. Preservation of signs of ED after the end of the treatment of leukemia indicates the need for cardiac monitoring of patients with ALL in history.
\end{abstract}

Key words: acute leukemia, children, endothelial dysfunction, nitric oxide.

Acute lymphoblastic leukemia (ALL) is associated with a large number of complications due to the disease itself and multicomponent therapy [1-3]. Infectious-toxic complications are particularly severe as they are more often lethal than relapse of leukemia [4]. The survival rate of children diagnosed with ALL has been improved due to anthracycline agents, but their use is accompanied by vascular endothelial damage with subsequent development of endothelial dysfunction (ED) $[5,6]$. Moreover, it has been

Corresponding Author:

Tetiana Kondratiuk - MD, PhD-student,

Department of pediatrics №2,

Kharkiv National Medical University,

Kharkiv, Ukraine, e-mail: kmnutetiana@gmail.com proved that ED is part of ALL phenotype in children [5, 7-9], which also explains the effect of anthracycline agents. Studies have shown that there are functional cross-links between hematologic malignancies and vascular endothelium [10]. Hematopoietic stem cells, including myeloid precursors, can integrate into existing functional vascular endothelium with differentiation into phenotypic and functional epithelial-like cells. It is claimed that vascular endothelium is an unrecognized reservoir for blast cells, which plays an important role in the pathogenesis and recurrence of leukemia [10].

Endothelial dysfunction can be defined as inappropriate (increased or reduced) formation in the endothelium of vessels of various biologically active substances. Reduced bioavailability of 
L-arginine, accelerated catalysis, or decreased concentration of nitric oxide (NO) is one of the foundations of ED [7].

The term "nitric oxide" refers to the reduced form of nitric oxide (NO) with a half-life of 2 to 30 seconds, which complicates the method of determining it in the blood. Indirect markers of nitric oxide concentration in the body are its more stable end products nitrite $\left(\mathrm{NO}_{2}\right)$ and nitrate $\left(\mathrm{NO}_{3}\right)$ [11]. It is the content of these metabolites that determines the total content of nitric oxide.

To date, it has been proven that ED is a common feature of many early complications of chemotherapy, which are a significant cause of morbidity and mortality, despite optimization of treatment protocols [5]. However, there is insufficient data on the role of ED markers in the treatment and remission of ALL in children [8].

\section{Purposes, subjects and methods}

2.1. The purpose of the work was to evaluate the profile of endothelial function during diagnosis and different periods of treatment and remission in children, to attest the presence of correlation of endothelial dysfunction markers with early adverse clinical outcome of ALL.

\subsection{Subjects and Methods}

\section{General}

The study was performed between 01 September 2016 and 01 November 2020. 73 children ( 49 boys and 24 girls) with ALL who were hospitalized at Kharkiv City Clinical Children's Hospital No. 16, were studied. The patients' age ranged from 1 to 17 years. The control group consisted of 19 healthy age- and gender-matched children brought to Kharkiv City Outpatient Hospital No. 16 for routine health control or vaccination.

The diagnosis of ALL was established according to the diagnostic criteria specified in the Acute Lymphoblastic Leukaemia Intensive Chemotherapy Berlin Frankfurt Munich 2009 (ALL IC BFM 2009) [12]. After the diagnosis has been established, the patients began an inductive chemotherapy course under the program ALL IC BFM 2009 [12].

The criteria for inclusion in the study were verified diagnosis of ALL, signed consent from parents and/or patients. The criteria for exclusion in the study were refusal of the parents or/and patients to sign the consent or death of patients.

Determination of nitric oxide metabolites

All 73 patients with ALL were involved in determination of the content of serum nitric oxide by spectrophotometric method with nitrogen oxide in M.O. Kovaleva et al. modification (2007) by concentration of its stable metabolites (oxidation products) of nitric oxide $-\mathrm{NO}_{2}, \mathrm{NO}_{3}$ [13]. The results of $\mathrm{NO}_{2}, \mathrm{NO}_{3}$ concentrations were expressed in $\mu \mathrm{mol} / 1$.

Determination of nitric oxide was performed at different stages of ALL presentation: 49 children were examined during the manifestation of leukemia (group 1A), of whom 36 children (group 1B) were re-examined during the first course of treatment-induction of remission. Also, 8 children (group 2) were examined during supportive therapy and 16 children (group 3) who underwent complete chemotherapy treatment and had a bone marrow remission period of 2 to 12 years.

Nineteen children in the control group were tested for nitric oxide once during a routine pediatric examination.

Ethics approval and consent to participate

Each study participant and his/her parents were informed about the nature of the study and signed a consent to participate in the study. The study was approved by Ethics and Bioethics Committee of Kharkiv National Medical University, Ukraine (Protocol No. 8 of $5^{\text {th }}$ October 2016) and was conducted according to Helsinki Declaration (1975).

\section{Statistical analyses}

For statistical analyses of data STATISTICA 8 (Tulsa, OK) was used. Shapiro-Vilka test was used for verification of the distribution according to the Gauss law. Non-parametric variables included median $(\mathrm{Me})$, interquartile range $[\mathrm{Lq}-$ lower quartile; Uq - upper quartile]. To compare the two dependent samples, the non-parametric Wilcoxon test (T) was used. To compare two independent samples, non-parametric MannWhitney U-test has been used. All P-values were two-tailed, and values $<0.05$ were considered significant. ROC analysis was used to evaluate the specificity and sensitivity of the method.

\section{Conflict of interests}

The authors of the article declare no conflict of interest.

\section{Results and discussion}

The study involved 73 children with ALL. General characteristics of patients are presented in Table 1. There was a significant $(\mathrm{p}=0.006)$ prevalence of boys $(67.0 \%)$ than girls $(33.0 \%)$. Patients had a median age of $6.7 \pm 5.0$ years (range 1 to 17 years).

Among the immunophenotypic variants of leukemia, B cell lineage leukemia was significantly more common $(\mathrm{p}=0.000)-60 / 73$ children $(82.2 \%)$. Only $13 / 73(17.8 \%)$ children had T cell lineage leukemia. 
Table 1

General characteristics of patients in diagnosis

\begin{tabular}{|c|c|c|}
\hline Characteristics & $\mathrm{n}=73$ & $\%$ \\
\hline Gender & $49 / 24$ & $67.0 / 33.0$ \\
male / female & 15 & 20.5 \\
\hline Age, years & 27 & 37.0 \\
$<3$ & 15 & 20.5 \\
$3-6$ & 5 & 15.0 \\
$7-10$ & 11 & $100 / 0$ \\
$11-14$ & $73 / 0$ & $78.3 / 21.7$ \\
$15-18$ & $36 / 10$ & $76.7 / 23.3$ \\
\hline Race & $56 / 17$ & \\
\hline European / Other & & \\
\hline Immunophenotype & lineage / T - lineage &
\end{tabular}

The level of metabolites of nitric oxide, namely nitrites $\left(\mathrm{NO}_{2}\right)$ and nitrates $\left(\mathrm{NO}_{3}\right)$ in the serum of children with ALL, was significantly different from the normal parameters of the control group (Table 2). Based on the fact that ED is a pathological increase or decrease in biologically active substances in the vascular endothelium [7], the deviations obtained from our control values confirm the manifestations of ED in all patients studied.

NO? content in patients of all groups (1A, $1 \mathrm{~B}, 2,3)$ was significantly higher than the nitrite level of the control group children (Table 2). $\mathrm{NO}_{2}$ had the opposite pattern and was significantly lower in patients with ALL than nitrate levels in healthy children. At the same time, despite the high concentration of $\mathrm{NO}_{2}$, the total amount of $\mathrm{NO}_{3}+\mathrm{NO}_{3}$ in children with ALL during all observation periods (manifestation, intensive care, supportive therapy and remission of leukemia) was significantly lower than in the control group children, with a maximum reduction during induction polychemotherapy (group 1B patients).

Adrian Doroszko et al., 2016 [9], Woo Jung Jang, 2013 [6] obtained similar results (reduction of NO content) and confirmed the pathogenic hypothesis of impaired NO synthesis in children with ALL. The low concentration of nitric oxide was explained by intensification of ED secondary

Table 2

Indicators of nitric oxide levels in children with acute lymphoblastic leukemia and controls $(\mathrm{Me}(L q ; U q))$

\begin{tabular}{|c|c|c|c|c|c|}
\hline \multirow{3}{*}{ Indicator } & \multicolumn{5}{|c|}{ Group } \\
\hline & \multicolumn{2}{|c|}{ Group 1} & \multirow{2}{*}{$\begin{array}{c}\text { Group } 2 \\
n=8\end{array}$} & \multirow{2}{*}{$\begin{array}{c}\text { Group } 3 \\
\mathrm{n}=16\end{array}$} & \multirow{2}{*}{$\begin{array}{l}\text { Control group } \\
n=19\end{array}$} \\
\hline & $\begin{array}{c}1 \mathrm{~A} \\
\mathrm{n}=49\end{array}$ & $\begin{array}{c}1 \mathrm{~B} \\
\mathrm{n}=34\end{array}$ & & & \\
\hline \multirow{3}{*}{$\begin{array}{l}\mathrm{NO}_{2} \\
\mu \mathrm{mol} / \mathrm{l}\end{array}$} & 17.55 & 19.56 & 21.10 & 20.54 & 12.79 \\
\hline & 11.12 & 13.56 & 20.42 & 17.80 & 12.35 \\
\hline & 21.28 & 24.15 & 22.13 & 24.44 & 14.00 \\
\hline \\
\hline \multicolumn{6}{|c|}{$\begin{array}{l}\text { W Test: } p_{1 A}-p_{1 Б}=0.0552 \\
\text { MW U Test: } p_{1 A}-p_{2}=\mathbf{0 . 0 4 6 5} ; p_{1 A}-p_{3}=\mathbf{0 . 0 3 4 6} ; p_{1 A}-p_{K}=\mathbf{0 . 0 1 5 0} ; p_{15}-p_{2}=0.2682 ; p_{15}-p_{3}=0.3911 \\
p_{15-} p_{K}=0.0002 ; p_{2}-p_{3}=0.6406 ; p_{2}-p_{K}=0.0000 ; p_{3}-p_{K}=\mathbf{0 . 0 0 0 0}\end{array}$} \\
\hline \multirow{3}{*}{$\begin{array}{l}\mathrm{NO}_{3} \\
\mu \mathrm{mol} / /\end{array}$} & 14.97 & 15.51 & 14.40 & 12.06 & 30.93 \\
\hline & 11.28 & 12.00 & 12.63 & 11.00 & 28.79 \\
\hline & 17.34 & 19.34 & 15.27 & 17.09 & 32.05 \\
\hline \multicolumn{6}{|c|}{ W Test: $p_{1 A}-p_{15}=0.0002$} \\
\hline \multicolumn{6}{|c|}{$\begin{array}{l}\text { MW U Test: } p_{1 A}-p_{2}=0.7598 ; p_{1 A}-p_{3}=0.3489 ; p_{1 A}-p_{K}=0.0000 ; p_{1 Б}-p_{2}=0.5476 ; p_{1 Б}-p_{3}=0.1044 ; \\
p_{15}-p_{K}=0.0000 ; p_{2}-p_{3}=0.6931 ; p_{2}-p_{K}=0.0000 ; p_{3}-p_{K}=0.0000\end{array}$} \\
\hline \multirow{3}{*}{$\mathrm{NO}_{2}+\mathrm{NO}_{3}, \mu \mathrm{mol} / \mathrm{l}$} & 30.64 & 33.55 & 35.83 & 35.54 & 42.27 \\
\hline & 27.86 & 31.45 & 34.10 & 28.36 & 41.51 \\
\hline & 35.28 & 39.19 & 37.91 & 42.10 & 45.61 \\
\hline
\end{tabular}

Note. W Test - Wilcoxon test, MW U Test - Mann-Whitney test 
to cytostatic therapy with anthracycline antibiotics and an increase in the production of NO synthetase inhibitors [6,9]. For example, asymmetric dimethylarginine (ADMA) is a competitive inhibitor of NO synthase and is increased in patients with ALL. ADMA is a product of tumor cell degradation, oxidative stress, manifestation of liver failure and inflammation of the endothelial wall $[5,8,9]$.

It should be noted that there are a number of scientific studies on the levels of nitric oxide in ALL, which have shown the results of increasing total NO [7, 14, 15]. However, studies were conducted on adult patients who likely had concomitant cardiovascular diseases.

When comparing nitrite levels across all groups, it was found that starting high $\mathrm{NO}_{2}$ content during leukemia manifestation (group 1A) continued to increase significantly $(p<0.05)$ at subsequent stages of treatment (induction therapy, supportive therapy, and during remission of ALL).

$\mathrm{NO}_{3}$ concentration remained at a level lower than normal throughout the study periods (manifestation, induction, supportive therapy and remission). No statistical significance was found between the patients of groups 1A, 2 and 3 ( $p>0.05$ ). Wilcoxon's test between $\mathrm{NO}_{3}$ groups $\mathrm{A}$ and $1 \mathrm{~B}$ demonstrated a significant $(p=0.0002)$ tendency to an increase in this index during complications of induction therapy compared to the acute phase of the disease.

Thus, at a low level of nitric oxide, an increase in nitrite values accompanied by a decrease in nitrate indicators was observed. A much higher nitrite content $\left(\mathrm{NO}_{2}\right)$ than nitrate level $\left(\mathrm{NO}_{3}\right)$ indicated severe tissue damage, endogenous intoxication [16] due to the manifestations of leukemia. Perhaps, secondary to a low total NO level, there were compensatory changes in the ratio of nitrogen metabolites in the form of an increase in $\mathrm{NO}_{2}$ level due to the inverse conversion of $\mathrm{NO}_{3}$ to $\mathrm{NO}_{2}$. In some conditions, the reaction of the nitrogen cycle may be dominated by the synthesis of NO from arginine, or its reduction from nitrite ion [16].

In patients of group $1 \mathrm{~A}$, direct correlation was found between the levels of metabolites of nitric oxide and indicators of humoral immunity (immunoglobulins A, G), circulating immune complexes, glycoproteins (Table 3). Thus, an increase in ED during the increase in the severity of leukemia and immunodeficiency was recorded. In addition, nitrogen metabolites showed a weak indirect correlation between blood pressure levels in patients during the onset of ALL, confirming the vasoactive function of nitric oxide [14].

Group 1B patients were found to have indirect correlations between $\mathrm{NO}_{2}, \mathrm{NO}_{2}+\mathrm{NO}_{3}$ and uric acid (Table 3), demonstrating an increase in ED during blast cell lysis. The metabolites of nitric oxide also had correlation with C-reactive protein, albumin $\alpha 1$-globulins and $\gamma$-globulins. The above indicates a close correlation of endothelial function with the intensity and severity of the inflammatory process in ALL.

In patients with remission of leukemia, after completion of treatment (group 3), the content of $\mathrm{NO}_{2}+\mathrm{NO}_{3}$ tended to increase, i.e. almost

Table 3

Correlation relationships between endothelial dysfunction markers, laboratory and physical indicators

\begin{tabular}{|c|c|c|c|}
\hline Laboratory value & $\begin{array}{c}\mathrm{NO}_{2} \\
\mu \mathrm{mol} / 1\end{array}$ & $\begin{array}{c}\mathrm{NO}_{3} \\
\mu \mathrm{mol} / 1\end{array}$ & $\begin{array}{c}\mathrm{NO}_{2}+\mathrm{NO}_{3}, \\
\mu \mathrm{mol} / 1\end{array}$ \\
\hline \multicolumn{4}{|c|}{ Group 1A $(n=49)$} \\
\hline Glycoproteins, U. & & $+0.536 *$ & \\
\hline CIC, U. & $+0.502 *$ & $+0.639 *$ & $+0.534 *$ \\
\hline Immunoglobulin $\mathrm{A}, \mathrm{g} / \mathrm{l}$ & $+0.581^{*}$ & & \\
\hline Immunoglobulin $\mathrm{G}, \mathrm{g} / \mathrm{l}$ & $+0.510^{*}$ & & \\
\hline Splenomegaly, cm & $+0.417^{*}$ & & \\
\hline $\begin{array}{c}\text { Blood pressure, } \\
\mathrm{mm} \mathrm{Hg}\end{array}$ & $-0.347 *$ & & $-0.411 *$ \\
\hline $\begin{array}{c}\text { Diastolic pressure, } \\
\mathrm{mm} \mathrm{Hg}\end{array}$ & $-0.355^{*}$ & & $-0.418 *$ \\
\hline \multicolumn{4}{|c|}{ Group 1B $(n=34)$} \\
\hline Uric acid, mmol/1 & $-0.898 *$ & & $-0.898 *$ \\
\hline C-reactive protein, $\mathrm{g} / \mathrm{l}$ & $+0.759 *$ & $-0.604^{*}$ & \\
\hline$\alpha 1$-globulins, $\%$ & $-0.696^{*}$ & & \\
\hline Albumins, $\%$ & & $-0.642 *$ & \\
\hline$\gamma$-gobulins, $\%$ & & $+0.541^{*}$ & \\
\hline
\end{tabular}


reached normal values. This is evidently due to the normalization of a number of NO synthetase inhibitors in children in remission [8] and the absence of pathological factors (remission of leukemia, end of treatment).

It should be emphasized that children who received anthracycline drugs are at risk of cardiovascular disease even after therapy $[6,9$, 17]. Persistence of a high $\mathrm{NO}_{2}$ concentration and a low $\mathrm{NO}_{3}$ concentration in the serum of patients during remission confirms incomplete endothelial recovery. This substantiates the need for cardiac monitoring of patients with ALL in history.

Influence of nitric oxide metabolite levels on the development of adverse complications

Five $(6.8 \%)$ patients out of 73 died. Of them, $3(4.1 \%)$ children died during the induction of remission from complications of ALL and chemotherapy. All three children had manifestations of multiple organ failure secondary to toxic ulcerative necrotic enteropathy, mucositis, respiratory failure, myelosuppression (neutropenia), and hemorrhagic syndrome. One child had bilateral pneumonia. The other child had acute renal failure and angioplastic encephalopathy.

The other 2 children died of recurrence of leukemia after the end of our study. To analyze the possible prognostic value of $\mathrm{NO}_{2}, \mathrm{NO}_{3}$ levels, their sums among patients of group $1 \mathrm{~B}$, who died during the development of complications during chemotherapy, ROC analysis was used. The results of the analysis showed that the $\mathrm{NO}_{2}$ level was lower than $12.31 \mu \mathrm{mol} / 1$ (Figure 1), predicts lethality with a sensitivity of $100 \%$ (95\% CI 29.2 -

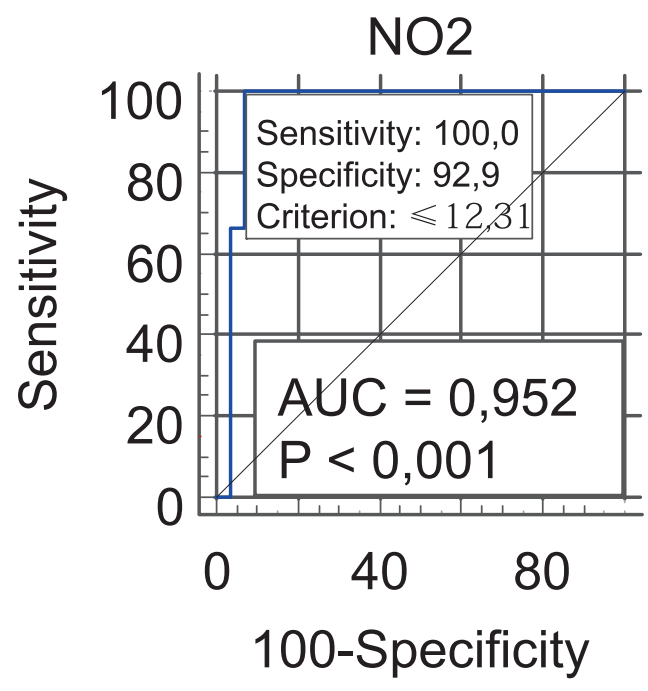

Figure 1. ROC curve predicting the likelihood of lethality according to $\mathrm{NO}_{2}$ level of patients $\mathrm{i}$ $n$ group $1 \mathrm{~B}$
100), specificity $92.9 \%$ (95\% CI 76.5-99.1) $(\mathrm{AUC}=0.952[0.81 ; 0.99]$. These data confirm the contribution of $\mathrm{NO}_{2}$ to the development of leukemia complications.

Reduction of biological activity of nitric oxide (NO) leads to stimulation of vasoconstriction, inflammation and thrombosis, damage to tissue structures, plays a crucial role in the pathogenesis of $\mathrm{ED}[5,8,16]$. The role of nitric oxide in disorders of cardiovascular function under conditions of endotoxic shock has been proved [16]. The timely detection of this process can have therapeutic and prognostic consequences $[5,8]$. We observed a maximum decrease in the total amount of nitrates and nitrites during induction polychemotherapy. ROC analysis confirmed (Figure 2) that the $\mathrm{NO}_{2}+\mathrm{NO}_{3}$ level was lower than $32.99 \mu \mathrm{mol} / 1$, predicting fatal complications with sensitivity of $100 \%$ (95\% CI 29.2 -100), specificity $92.9 \%$ (95\% CI $37.2-$ 75.5) $(\mathrm{AUC}=0.810[0.62 ; 0.92])$

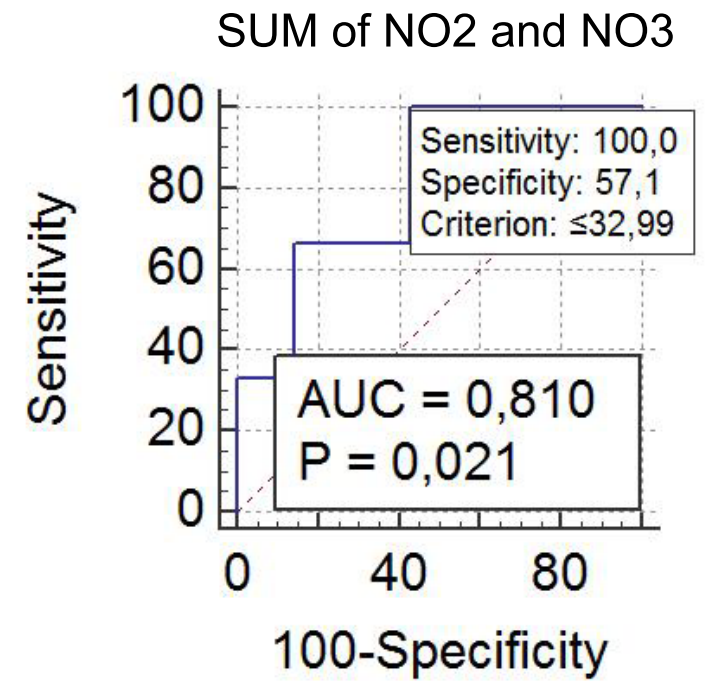

Figure 2. ROC curve predicting the likelihood of death according to the level of the sum of $\mathrm{NO}_{2}$ and $\mathrm{NO}_{3}$ patients in group $1 \mathrm{~B}$

$\mathrm{NO}_{3}$ concentrations did not show any correlation between their content and reliable likelihood of severe clinical adverse events (Table 4).

Thus, the critical localization of endothelial cells between circulation and other components of the vascular wall places them in the pathophysiological bed of cardiovascular and other consequences of oncohematological diseases [5]. Inflammatory and pro-aggregation activation of the endothelium is common in children with ALL [5, 7-9]. Therefore, ALL should be regarded as a multiple organ disease, and ED as an integral part of the pathogenic link of leukemia [9] and its complications. 
Table 4

ROC indicators of NO? levels and lethal complications of induction therapy in acute lymphoblastic leukemia

\begin{tabular}{|l|c|c|c|c|c|c|c|c|}
\hline Parameter & AUC & "cut-off point" & Se, $\%$ & $95 \% \mathrm{Cl}$ & $\mathrm{Sp}, \%$ & $95 \% \mathrm{Cl}$ & $+\mathrm{LR}$ & -LR \\
\hline $\mathrm{NO}_{3,}, \mu \mathrm{mol} / \mathrm{l}$ & 0.518 & $\leqslant 7$ & 33.33 & $0.8-90.6$ & 100 & $87.7-100$ & - & 0.67 \\
\hline
\end{tabular}

\section{Conclusions}

Our study determined significant violations of nitric oxide synthesis in the form of nitrite increase and nitrate reduction secondary to reduced total nitric oxide content. This confirms that ED accompanies the course of ALL in children.

The negative effects on the cardiovascular system of the concentration of nitric oxide and its metabolites in ALL in children are well known. There is a lack of information on the likely role of these markers in the pathogenesis of other (toxic, infectious) complications. The findings of our work demonstrate that the determination of nitric oxide is of diagnostic and prognostic significance in patients with ALL. The critical fall in the concentration of $\mathrm{NO}$ and $\mathrm{NO}_{2}$ accompanies the development of multiple organ failure with fatal outcome in children with ALL.

Due to the preservation of the signs of ED after the end of treatment in children with ALL, it is necessary to monitor the state of functioning of the cardiovascular system in the future.

\section{Acknowledgements}

The authors thank the young patients and parents for their trust and participation in the study.

The authors are grateful to the staff of Kharkiv City Children's Hospital No. 16 for making this research possible. This study was supported by the Kharkiv National Medical University (No. 108U005255). The funder had no role in the study design, data collection and analysis, decision to publish, or preparation of the paper.

\section{References}

1. Giddings B.M., Whitehead T.P., Metayer C. (2016) Childhood leukemia incidence in California: High and rising in the Hispanic population. Cancer. Vol. 15;122 (18). - P. 2867-2875. doi: 10.1002/ cncr.30129.

2. Inaba H., Pei D., Wolf J., Howard C., Hayden R.T., et al. (2017) Infection-related complications during treatment for childhood acute lymphoblastic leukemia. Annals of Oncology. Vol. 28. - P. 386392. doi: 10/1093/annonc/mdw557.

3. Hough R., Vora A. (2017) Crisis management in the treatment of childhood acute lymphoblastic leukemia: putting right what can go wrong (emergency complications of disease and treatment). Hematology. Vol. 8. - P. 251-258.

4. O'Connor D., Bate J., Wade R., Clack R., Dhir S., et al. (2014) Infection-related mortality in children with acute lymphoblastic leukemia: an analysis of infectious deaths on UKALL2003. Blood. Vol. 124 (7). - P. 1056-1061.

5. Doroszko A., Niedzielska E., Jakubowski M., Porwolik J., Turek-Jakubowska A., et al. (2018) Endothelial function in children with acute lymphoblastic leukemia (ALL) may reflect the clinical outcome. Hindawi BioMed Research International. Vol. 2018. - 8 pages. - doi: 10.1002/bjs. 1800700111.

6. Woo Jung Jang, Duk Yong Choi, In-Sang Jeon (2014) Vascular endothelial dysfunction after anthracyclines, treatment in children with acute lymphoblastic leukemia. Korean J. Pediatr. Vol. 56 (3). P. $130-134$.

7. Skypnyk I., Maslova G., Lymanets T., Gusachenko I. (2017) L-arginine is an effective medication for prevention of endothelial dysfunction, a predictor of anthracycline cardiotoxicity in patients with acute leukemia. Exp. Oncol.Vol. 39 (4). - P. 308-311.

8. Masopustova A., Jehlicka P., Huml M., Votava T., Trefil L., et al. (2018) Plethysmographic and biochemical markers in the diagnosis of endothelial dysfunction in pediatric acute lymphoblastic leukemia survivors - new applications. Physiol. Res. Vol. 67. - P. 903-909.

9. Doroszko A., Niedzielska E., Jakubowski M., Porwolik J., Turek-Jakubowska A., et al. (2016) Elevated plasma ADMA contributes to development of endothelial dysfunction in children with acute lymphoblastic leukemia. Postery Hig. Med. Dosw. Vol. 70. - P. 562-571.

10. Cogle C.R., Goldman D.C., Madlambayan G.J., Leon R.P., Masri A.A., et al. (2014) Functional integration of acute myeloid leukemia into the vascular niche. Leukemia. Vol. 28 (10). - P.1978-1987. doi: 10.1038/leu.2014.109. 
11. Komarevtseva I.A, Orlova E.A, Tarasova M.V, Soloviev I.V., Komarevtseva E.V., et al. (2009) The level of nitric oxide in tissues, serum, mononuclear and mesenchymal stem cells. Ukrainian Journal of Clinical and Laboratory Medicine.Vol.4, No. 4. - P. 133-137.

12. Acute Lymphoblastic Leukaemia Intensive Chemotherapy Berlin Frankfurt Munich 2009. A Randomized Trial of the I-BFM-SG for the Management of Childhood non-B Acute Lymphoblastic Leukemia. Final Version of Therapy Protocol from August-14-2009. http://www.bialaczka.org/wp-content/ uploads/2016/10/ALLIC_BFM_2009.pdf (Accessed on October, 2016).

13. Kovaleva, GV Demidenko, TV Humpback (2007) Diagnosis of endothelial function - assessment of the vasoactive pool of nitric oxide: method. Ministry of Health of Ukraine, Ukrainian Center for Scientific Medical Information and Patent Licensing. P. 16.

14. Ghaffari M.A., Kadkhodaei-Elyaderani M., Saffari M.R., Pedram M. (2005) Monitoring of serum nitric oxide in patients with acute leukemia. Iranian journal of pharmaceutical research. Vol. 4. P. 233-237.

15. Meng Bing (2006) Significanceof serum levels of interleukin-18 and nitric oxide during tumor growth and recrudescence in children with acute lymphoblastic leukemia. Appl. clin. pediatr. Vol. 21 (3). P.158-159.

16. Vinnik YA, Bagmut IY, Zhukov VI, Moiseenko AS, Efimova GS (2019) Gastric cancer: current methods of prenatal diagnosis and features of surgical treatment. Kharkiv. - Gold pages. - P. 121-142.

17. Giordano P., Muggeo P., Delvecchio M., Carbonara S., Romano A., et al. (2017) Endothelial dysfunction and cardiovascular risk factors in childhood acute lymphoblastic leukemia survivors . Int. J. Cardiol. Vol. 1 (228). - P. 621-627. doi: 10.1016/j.ijcard.2016.11.025.

Received: 13-Dec-2019

Accepted: 01-Mar-2020 